\title{
DELPHI TECHNIQUE: CONSENSUS OF ANATOMY CIRCULATORY SYSTEM CORE SYLLABUS FOR MEDICAL STUDENT
}

\author{
Siti Munawaroh*, Farhah Millata Hanifa**, Nanang Wiyono*, Yunia Hastami*, M. Nur Dewi \\ Kartikasari***, Bulan Kakanita Hermasari**** \\ * Department of Anatomy and Embryology, Faculty of Medicine, Universitas Sebelas Maret, \\ Surakarta - INDONESIA \\ ** Undergraduate Medical Student, Faculty of Medicine, Universitas Sebelas Maret, \\ Surakarta - INDONESIA \\ *** Midwifery Programme, Faculty of Medicine, Universitas Sebelas Maret, Surakarta - INDONESIA \\ **** Medical Education Unit, Faculty of Medicine, Universitas Sebelas Maret, Surakarta - INDONESIA
}

\section{ABSTRACT}

Background: Anatomy is a very important basic science in medical education. However, the advance of science and technology affected medical curriculum. One of the changes is the decreased time available for anatomy learning. Therefore, an anatomy lecturer needs to sort and choose from many existing anatomical materials to adjust with time allocation. The purpose of this study is to gain consensus on what minimum anatomical knowledge is for a physician candidate in order to practice safely.

Method: This study was design in qualitative approach with two round Delphi Technique. Using purposive sampling method, the subjects of the study were 20 general-physicians in Indonesia. The questionnare was arranged based on anatomy text book and the research about anatomic core syllabus. The firts Delphi aimed to select the anatomical course material and additional course material. The second Delphi round intended to provide level range from 1-4. The consensus level established by researcher at $60 \%$ point.

Results: There is not any additional topics in the first Delphi round. So the number of first and second round topics is 270 topics. The Delphi second round agree that anatomic core syllabus of circulation system is 110 of 270 topics. There are 30 topics of cor, 3 topics of pericardium, 10 topics of mediastinum, 37 topics of artery, 9 topics of vena, 9 topics of lymphathic system, 4 topics of postnatal circulation, 5 topics of prenatal circulation, and 3 topics of portal hepatic system. Conclusion: The anatomy core syllabus consists of 110 of the 270 anatomical circulatory system topics.

Keywords: core syllabus, anatomy circulation system, general physician consensus, Delphi technique.

\section{TEKNIK DELPHI: KONSENSUS MATERI ANATOMI SISTEM SIRKULASI UNTUK MAHASISWA KEDOKTERAN}

\begin{abstract}
ABSTRAK
Latar belakang: Anatomi merupakan ilmu dasar yang sangat penting dalam pendidikan kedokteran. Akan tetapi, adanya kemajuan yang cepat dari ilmu pengetahuan dan teknologi telah mengubah kurikulum kedokteran. Salah satu perubahan yang ada adalah berkurangnya waktu yang tersedia untuk pembelajaran anatomi. Seorang dosen anatomi perlu memilih dari sekian banyak materi anatomi yang ada untuk menyesuaikan alokasi waktu yang tersedia. Tujuan penelitian ini adalah untuk mendapatkan konsensus mengenai pengetahuan anatomi minimum yang perlu dimiliki oleh seorang calon dokter umum.

Metode: Penelitian ini merupakan penelitian kualitatif dengan metode Delphi 2 putaran. Subyek penelitian adalah dokter umum di Indonesia berjumlah 20 orang yang dipilih melalui purposive sampling. Kuesioner awal disusun oleh peneliti berdasarkan tiga buku teks dan penelitian tentang materi inti anatomi sebelumnya.
\end{abstract}

contact: munafkuns@gmail.com 
Pada Delphi putaran pertama panel mencentang topik anatomi yang penting dan menambahkan jika ada topik yang belum ditulis. Sedangkan pada Delphi putaran kedua panel memberi rangking 1-4 sesuai tingkat pentingnya topik tersebut. Level konsensus yang ditetapkan peneliti sebesar 60\%.

Hasil: Pada Delphi putaran pertama tidak didapatkan tambahan topik. Sehingga jumlah topik putaran pertama dan kedua sama yaitu 270 topik. Delphi putaran kedua didapatkan 110 materi inti dengan perincian materi jantung sebanyak 30 topik, pericardium 3 topik, mediastinum 10 topik, pembuluh darah arteri 37 topik, pembuluh darah vena 9 topik, sistem limfatik 9 topik, sirkulasi pascanatal 4 topik, sirkulasi prenatal 5 topik, dan sistem portal hepatis 3 topik.

Kesimpulan: Konsensus dokter umum dari penelitian ini didapatkan sebanyak 110 materi inti dari 270 materi anatomi sistem sirkulasi.

Kata kunci: materi inti, anatomi sistem sirkulasi, konsensus dokter umum, teknik Delphi.

\section{PENDAHULUAN}

Materi anatomi telah lama diakui menjadi materi yang penting bagi semua bidang kedokteran. ${ }^{1}$ Para ahli medis sepakatbahwa pendidikan anatomi merupakan elemen penting dari kurikulum kedokteran. Mereka menyebutkan bahwa pembelajaran anatomi merupakan kegiatan yang menguji profesionalitas di tingkat praklinis, sehingga dapat membantu menumbuhkan identitas profesionalisme di tingkat klinis, dan meningkatkan kompetensi di berbagai bidang, seperti kerja sama tim, komunikasi, dan etika dokter. $^{2}$ Penelitian sebelumnya telah menunjukkan bahwa seorang dokter harus menggunakan pengetahuan anatominya dalam semua tahap pemeriksaan, terutama selama pemeriksaan fisik, penalaran diagnostik dan pengambilan keputusan klinis. ${ }^{3}$

Kemajuan teknologi termasuk didalamnya kemajuan pendidikan di berbagai negara telah mempengaruhi kurikulum kedokteran. Ada dua realitas yang secara langsung bersaing di tingkat praklinis. Pertama, adanya ekspansi yang cepat dari pengetahuan dalam disiplin ilmu kedokteran dasar sehingga membutuhkan waktu mengajar lebih banyak. Kedua adanya kecenderungan kuat untuk mengurangi waktu belajar terutama dalam kurikulum baru atau kurikulum berbasis masalah. ${ }^{4}$

Proses pembelajaran pada kurikulum baru berpusat kepada mahasiswa. Menurut beberapa penelitian yang mengevaluasi dampak dari kurikulum ini di laboratorium anatomi menunjukkan bahwa metode pembelajaran yang berpusat pada mahasiswa secara signifikan meningkatkan kinerja mahasiswa dalam ujian. ${ }^{5,6}$ Namun, dalam konteks tertentu, terdapat dampak negatif berupa pengurangan waktu belajar. ${ }^{7}$ Dampak negatif ini merupakan aspek sulit bagi beberapa dosen. Ada beberapa kasus yaitu dosen tidak berpegang pada batas waktu sehingga ketika waktu belajar telah habis mereka melanjutkan kuliah pada waktu istirahat atau makan siang. Oleh sebab itu dosen mencoba untuk merevisi isi kuliah dengan tujuan agar sesuai dengan waktu yang ditentukan. Sebagian besar dosen beradaptasi dengan baik terhadap perubahan tersebut dan membuat upaya yang baik untuk merevisi isi kuliah agar sesuai dengan kurikulum baru. ${ }^{8}$ Agar materi yang diajarkan dan dihilangkan sesuai dengan kompetensi dokter umum, maka dosen anatomi perlu memilih secara tepat materi yang seharusnya dipelajari oleh mahasiswa kedokteran. ${ }^{9}$

Dengan dasar tersebut peneliti bermaksud menyusun konsensus untuk merangkum pengetahuan anatomi minimum yang perlu dimiliki oleh seorang calon dokter umum agar bisa berpraktik dengan aman. Diharapkan dari hasil penelitian ini dapat membantu untuk memudahkan dosen anatomi kedokteran dalam menentukan materi anatomi yang perlu dipelajari mahasiswa. Dengan demikian mahasiswa bisa belajar anatomi dengan lebih fokus dan terarah sehingga bisa menjadi dasar pemahaman untuk memasuki dunia praktik sebagai dokter umum setelah lulus nanti. Penelitian mengenai materi anatomi telah dilakukan sebelumnya. Sebagian 
besar penelitian menggunakan metode Delphi, yaitu suatu metode yang digunakan untuk menyelaraskan proses komunikasi suatu grup sehingga dicapai proses yang efektif guna mendapatkan solusi suatu permasalahan yang kompleks. ${ }^{10}$ Diantaranya adalah studi konsensus Delphi untuk mengidentifikasi komponen anatomi orthopedi klinis oleh Swamy et al, ${ }^{11}$ pengembangan materi inti untuk pengajaran anatomi kepala dan leher oleh Tubbs et $a{ }^{12}{ }^{12}$ dan pengembangan materi inti untuk pengajaran sistem neurologi oleh Moxham et a ${ }^{13}$ yang ketiga penelitian diatas dilakukan pada pada tahun 2014. Kemudian pada tahun 2016 terdapat penelitian tentang materi inti anatomi tubuh secara umum oleh Smith et al..$^{14}$ Adapun yang sudah dilakukan di Indonesia adalah penelitian Munawaroh pada tahun 2016 mengenai Konsensus materi anatomi untuk mahasiswa pendidikan dokter. ${ }^{9}$ Penelitian ini merupakan penelitian lanjutan dari penelitian tersebut yang lebih memfokuskan pada sistem sirkulasi.

\section{METODE}

Penelitian ini merupakan penelitian kualitatif dengan metode Delphi. Tujuannya adalah untuk mendapatkan konsensus dari pakar mengenai materi inti anatomi sistem sirkulasi yang harus dimiliki oleh mahasiswa kedokteran sebagai bagian dari pengembangan kurikulum kedokteran. Metode Delphi dilakukan dalam dua putaran dengan menggunakan kuesioner sebagai instrumennya.

Pada kuesioner putaran pertama, peneliti akan menyajikan serangkaian pernyataan dimana panel diminta untuk menilai secara jelas pernyataan tersebut apakah pernyataan tersebut penting dalam suatu topik pembahasan. Isi pernyataannya berasal dari literatur dan temuan penelitian sebelumnya. ${ }^{15}$ Isi pernyataan berupa daftar materi anatomi sistem sirkulasi diambil dari buku teks yaitu Gray's anatomy for student karya Drake et $a 1,{ }^{16}$ Clinically Oriented Anatomy karya Moore et al, ${ }^{17}$ Sobotta, Atlas of Human Anatomy, Latin Nomenclature, ${ }^{18}$ dan juga hasil penelitian konsensus pakar anatomi mengenai materi inti anatomi kedokteran terutama pada bagian sistem sirkulasi oleh Munawaroh. ${ }^{9}$ Hasil kuesioner yang telah disusun kemudian dikonsultasikan kepada pakar anatomi, yaitu Dosen anatomi yang sudah mengajar anatomi lebih dari 10 tahun dan rutin mengikuti pertemuan ahli anatomi dalam PIN PAAI (Pertemuan Ilmiah Nasional Perhimpunan Ahli Anatomi Indonesia).

Pada Delphi putaran pertama kuesioner dibagikan kepada panel Delphi untuk menentukan materi anatomi sistem sirkulasi yang dibutuhkan dokter umum dalam praktik sehari-hari. Panel diminta untuk mencentang daftar materi yang dianggap penting dan menambahkan materi yang belum tercantum di dalam daftar tersebut. Setelah semua kuesioner putaran pertama kembali maka peneliti merangkum materi apa saja yang penting untuk dimasukkan ke Delphi putaran berikutnya. Materi bisa masuk ke Delphi putaran kedua jika minimal ada lima panel yang menyebutkan bahwa materi tersebut penting dan juga bila ada materi baru yang ditambahkan oleh panel pada putaran pertama.

Pada Delphi putaran kedua, panel diminta memberi rangking 1-4 tergantung seberapa penting materi tersebut berguna untuk dokter umum. Semakin besar nilainya maka semakin penting materi tersebut. Adapun level konsensus yang ditetapkan dalam penelitian ini sebesar $60 \%$. Oleh karena itu materi anatomi sistem sirkulasi dianggap penting apabila didapatkan minimal $60 \%$ panel delphi memilih angka 3 (penting) dan 4 (sangat penting).

Pada saat pengisian kuesioner baik pada Delphi putaran pertama maupun putaran kedua, panel Delphi diminta untuk memperhatikan level kompetensi dokter umum yang sudah ditetapkan dalam standar kompetensi dokter Indonesia (SKDI) 2012.

Subjek penelitian ini dipilih mengggunakan teknik purposive sampling. disesuaikan dengan kriteria inklusi, yaitu dokter umum yang sudah berpraktik minimal 3 tahun dan lulus dari sekolah kedokteran tidak lebih dari 10 tahun.

Penelitian ini dilaksanakan pada bulan Juni sampai dengan Agustus 2017. Adapun Persetujuan etik dikeluarkan oleh komite etik RSUD Dr. Moewardi dengan No. 531/VI/HREC/2017. 


\section{HASIL DAN PEMBAHASAN}

Pada Delphi putaran pertama, subjek penelitian yang terlibat dalam penelitian ini adalah sejumlah 23 panel. Namun dari 23 kuesioner yang disebar kepada 23 panel tersebut, yang kembali kepada peneliti hanya 21 kuesioner (91.3\%). Sementara pada Delphi putaran kedua, dari 21 kuesioner yang disebar yang kembali kepada peneliti sejumlah 20 kuesioner (95.2\%).

Panel yang terlibat dalam penelitian ini berasal dari berbagai kota besar di Indonesia, yaitu Jakarta, Depok, Bekasi, Semarang, Yogyakarta, Klaten, Surakarta, Mojokerto, Banyuwangi, Padang, dan Maluku Tenggara. Adapun asal universitas tempat mereka belajar kedokteran juga cukup bervariasi, yaitu dari 9 fakultas kedokteran ternama yang tersebar di Indonesia.
Kuesioner awal terdiri dari 9 topik materi sistem sirkulasi yaitu: jantung, pericardium, mediastinum, arteri, vena, sistem limfatik, sirkulasi darah manusia (pascanatal), sirkulasi darah fetus (prenatal), dan sistem portal hepatis. Total poin atau struktur anatomis dalam kuesioner ini adalah 270 poin. Pada Delphi putaran pertama dari 270 poin yang disebar kepada 21 panel semua masuk kembali ke putaran kedua dan tidak didapatkan poin atau struktur tambahan dari panel Delphi.

Hasil Delphi putaran kedua didapatkan 110 materi inti dari 270 materi atau sekitar 40.74\%. Sementara materi yang tidak dipilih oleh para panel untuk menjadi materi inti sebanyak 160 materi atau sekitar $59.25 \%$.

Tabel 1. Jumlah Topik Inti Pada Setiap Sub Sistem Sirkulasi

\begin{tabular}{clcc} 
No & \multicolumn{1}{c}{ Sub Sistem Sirkulasi } & Jumlah Topik Awal & Jumlah Topik Inti \\
1. & Jantung & 69 & 30 \\
2. & Pericardium & 10 & 3 \\
3. & Mediastinum & 11 & 10 \\
4. & Arteri & 92 & 37 \\
5. & Vena & 58 & 9 \\
6. & System limfatik & 10 & 9 \\
7. & Sirkulasipascanatal & 6 & 4 \\
8. & Sirkulasi prenatal & 5 & 5 \\
9. & Sistem portal hepatis & 9 & 3 \\
\hline & Total & 270 & 110 \\
\hline
\end{tabular}


Rincian persentase tiap topik sistem sirkulasi dijabarkan pada tabel 2 hingga 10 berikut ini.

Tabel 2. Daftar Topik jantung yang masuk dalam materi inti

\begin{tabular}{|c|c|c|}
\hline No & Topik & $\begin{array}{c}\sum \text { Panel memilih sebagai level } 3 \text { dan } 4 \\
\text { (\%) (n=20 orang) }\end{array}$ \\
\hline 1. & Fungsi jantung & $20(100)$ \\
\hline 2. & Proyeksi jantung & $20(100)$ \\
\hline 3. & Orientasi jantung & $20(100)$ \\
\hline 4. & Ventriculus sinistra & 19(95) \\
\hline 5. & Ventriculus dextra & 19(95) \\
\hline 6. & Atrium sinistrum & $18(90)$ \\
\hline 7. & Atrium dextrum & $19(95)$ \\
\hline 8. & Apex cordis & $19(95)$ \\
\hline 9. & Valva aortae & $16(80)$ \\
\hline 10. & Valva mitralis & $20(100)$ \\
\hline 11. & Valva tricuspidalis & $20(100)$ \\
\hline 12. & Valva trunci pulmonalis & $17(85)$ \\
\hline 13. & Arteri pulmonalis dextra et sinistra & $17(85)$ \\
\hline 14. & Arteri coronaria dextra et sinistra & $18(90)$ \\
\hline 15. & Nervus vagus & $17(85)$ \\
\hline 16. & Mm. papillares & $12(60)$ \\
\hline 17. & Epicardium & $14(70)$ \\
\hline 18. & Myocardium & $15(75)$ \\
\hline 19. & Endocardium & $14(70)$ \\
\hline 20. & Basis cordis & $14(70)$ \\
\hline 21. & Valvula semilunaris & $15(75)$ \\
\hline 22. & Cabang-cabang A. coronaria & $14(70)$ \\
\hline 23. & V. pulmonalis dextra et sinistra & $14(70)$ \\
\hline 24. & Septum interatriale & $13(65)$ \\
\hline 25. & Septum interventrikulare & $13(65)$ \\
\hline 26. & Fossae ovale & $13(65)$ \\
\hline 27. & Chorda tendineae & $14(70)$ \\
\hline 28. & Nodus sinuatrial & $14(70)$ \\
\hline 29. & Nodus atrioventrikularis & $14(70)$ \\
\hline 30. & N. laryngeus recurrens & $13(65)$ \\
\hline
\end{tabular}

Tabel 3. Daftar Topik Pericardium yang masuk dalam materi inti

\begin{tabular}{clc} 
No & \multicolumn{1}{c}{ Topik } & $\begin{array}{c}\text { P Panel memilih sebagai level } 3 \text { dan } \\
4(\%)(\mathbf{n}=20 \text { orang })\end{array}$ \\
\hline 1. & Cavum pericardii & $16(80)$ \\
2. & Pericardium fibrosum & $13(65)$ \\
3. & Pericardium serosum & $12(60)$ \\
\hline
\end{tabular}


Tabel 4. Daftar Topik Mediastinum yang masuk dalam materi inti

\begin{tabular}{|c|c|c|}
\hline No & Topik & $\begin{array}{c}\sum \text { Panel memilih sebagai level } 3 \\
\text { dan } 4(\%)(\mathrm{n}=20 \text { orang })\end{array}$ \\
\hline 1. & Fungsi mediastinum & $17(85)$ \\
\hline 2. & Mediastinum superior & $16(80)$ \\
\hline 3. & Mediastinum inferior & $16(80)$ \\
\hline 4. & Organ-organ pada mediastinum & $17(85)$ \\
\hline 5. & Nervus phrenicus & $16(80)$ \\
\hline 6. & Skeletopis mediastinum superius et inferius & $13(65)$ \\
\hline 7. & Truncus sympathicus & $15(75)$ \\
\hline 8. & N. splanchnicus & $15(75)$ \\
\hline 9. & Nn. Thoracici & $13(65)$ \\
\hline 10. & Nn. Intercostales & $13(65)$ \\
\hline
\end{tabular}

Tabel 5. Daftar Topik Arteri yang masuk dalam materi inti

$\begin{array}{cc}\text { No } & \text { Topik } \\ & 4 \text { Panel memilih sebagai level } 3 \text { dan } \\ \end{array}$

1. Arcus aortae

19(95)

2. Aortae ascendens

18(90)

3. Aortae descendens pars thoracica

$18(90)$

4. Aortae descendens pars abdominalis

18(90)

5. A. carotis communis sinistra

$16(80)$

6. A. carotis communis dexter

$16(80)$

7. A. carotis externa

8. A. cerebri anterior

9. A. cerebri media

10 A. radialis

11. A. femoralis

12. A. tibialis

13. A. dorsalis

14. Truncus brachiocephalicus

15. A. subclavia sinistra

16. A. subclavia dextra

17. A. intercostalis anterior 
18. A. intercostalis posterior 12(60)

19. A. thyroidea superior 13(65)

20. A. carotis interna 15(75)

21. A. ophtalmica 13(65)

22. A. communis posterior 13(65)

23. A. choroidea 12(60)

24. A. axillaris 13(65)

25. A. vertebralis 12(60)

26. A. ulnaris 14(70)

27. A. illiaca interna 12(60)

28. A. illiaca exterma 12(60)

29. A. umbilicalis 14(70)

30. A. uterine 13(65)

31. A. vaginalis 12(60)

32. A. popliteal 13(65)

33. A. malleolaris 15(75)

34. A. plantaris 14(70)

35. A. tarsalis 12(60)

36. A. mesenterica superior 12(60)

37. Kapiler 12(60)

Tabel 6. Daftar Topik Vena yang masuk dalam materi inti

\begin{tabular}{|c|c|c|}
\hline No & Topik & $\begin{array}{c}\sum \text { Panel memilih sebagai level } 3 \\
\text { dan } 4(\%)(n=20 \text { orang })\end{array}$ \\
\hline 1. & Vena cava superior & $20(100)$ \\
\hline 2. & Vena cava inferior & $19(95)$ \\
\hline 3. & Vena mediana cubiti & $16(80)$ \\
\hline 4. & V. jugularis externa & $15(75)$ \\
\hline 5. & V. jugularis interna & $14(70)$ \\
\hline 6. & V. subclavia & $14(70)$ \\
\hline 7. & V. saphena magna & $15(75)$ \\
\hline 8. & V. saphena parva & $13(65)$ \\
\hline 9. & V. femoralis & $14(70)$ \\
\hline
\end{tabular}


Tabel 7. Daftar Topik Sistem Limfatik yang masuk dalam materi inti

\begin{tabular}{clc} 
No & \multicolumn{1}{c}{ Topik } & $\begin{array}{c}\text { Peanel memilih sebagai level } 3 \\
\text { dan } 4(\%)(\mathbf{n}=20 \text { orang })\end{array}$ \\
1. & Vasa limfatik & $17(85)$ \\
2. & Nodi lymphatici cervicales & $18(90)$ \\
3. & Nodi lymphatici axillares & $19(95)$ \\
4. & Nodi lymphatici femoralis & $18(90)$ \\
5. & Nodi lymphatici popliteal & $17(85)$ \\
6. & Nodi lymphatici inguinales & $18(90)$ \\
7. & Nodi lymphatici profundi & $14(70)$ \\
8. & Ductus lymphaticus & $14(70)$ \\
9. & Ductus thoracicus & $12(60)$ \\
\hline
\end{tabular}

Tabel 8. Daftar Topik Sirkulasi Darah Manusia (Pascanatal) yang masuk dalam materi inti

\begin{tabular}{clc} 
No & Topik & $\begin{array}{c}\sum \text { Panel memilih sebagai level } 3 \\
\text { dan } 4(\%)(\mathbf{n}=20 \text { orang })\end{array}$ \\
\hline 1. & Sirkulasi darah magna & $14(70)$ \\
2. & Sirkulasi darah parva & $13(65)$ \\
3. & Ligamentum arteriosum & $13(65)$ \\
4. & Ligamentum venosum & $12(60)$ \\
\hline
\end{tabular}

Tabel 9. Daftar Topik Sirkulasi Darah Fetus (Prenatal) yang masuk dalam materi inti

\begin{tabular}{|c|c|c|}
\hline No & Topik & $\begin{array}{c}\sum \text { Panel memilih sebagai level } 3 \\
\text { dan } 4(\%)(\mathrm{n}=20 \text { orang })\end{array}$ \\
\hline 1. & Foramen ovale & $16(80)$ \\
\hline 2. & Vena umbilicales & $16(80)$ \\
\hline 3. & Arteri umbilicales & $16(80)$ \\
\hline 4. & Ductus arteriosus & $15(75)$ \\
\hline 5. & Ductus venosus & $12(60)$ \\
\hline
\end{tabular}

Tabel 10. Daftar Topik Sirkulasi Portal Hepatis yang masuk dalam materi inti

\begin{tabular}{lrl} 
No & Topik & $\begin{array}{c}\text { } \\
\text { Panel memilih sebagai level } 3 \text { dan } 4(\%)(\mathrm{n}=20 \\
\text { orang) }\end{array}$ \\
1. & Vena portae hepatis & $16(80)$ \\
2. & Dutus choledochus & $14(70)$ \\
3. & Vv. Hepatica & $12(60)$ \\
\hline
\end{tabular}


Subjek penelitian atau panel Delphi pada penelitian ini adalah dokter umum yang tersebar di beberapa daerah di Indonesia. Alasan peneliti memilih dokter umum untuk menjadi panel Delphi adalah agar materi inti yang dihasilkan benar-benar merupakan materi anatomi yang memang diperlukan oleh dokter umum saat berpraktik. Sehingga waktu pembelajaran yang terbatas bisa lebih efektif digunakan untuk pencapaian kompetensi sesuai standar kompetensi dokter yang sudah ditetapkan. Panel Delphi yang terlibat dalam penelitian ini berbeda dengan penelitian sebelumnya yang memilih pakar anatomi sebagai panel seperti pada penelitian Munawaroh et al, ${ }^{9}$ Moxham et al, ${ }^{13}$ dan Tubbs et al. ${ }^{12}$ Sementara Swamy et $\mathrm{al}^{11}$ dan Smith et $\mathrm{al}^{14}$ memilih dokter spesialis untuk menjadi panel Delphi. Peneliti tidak memilih dokter spesialis untuk menjadi panel dalam penelitian ini karena dikhawatirkan hasil yang didapatkan terlalu detail dan terspesialisasi sehingga dengan waktu pembelajaran anatomi yang minimal mahasiswa tidak dapat optimal dalam mempelajarinya.

Setelah para panel mengumpulkan kuesioner pada putaran kedua, peneliti merangkum hasil dari jawaban para panel tersebut. Peneliti menemukan banyak perbedaan pendapat antar panel. Ada panel yang menganggap suatu struktur penting, tetapi ternyata panel lain menganggap struktur tersebut tidak penting. Oleh karena itu untuk mendapatkan konsensus diperlukan identifikasi persentase level consensus yang akan ditetapkan. Secara umum tidak ada aturan untuk menentukan persentase tersebut pada penelitian Delphi. ${ }^{19}$ Konsensus akan muncul pada persentase level yang tinggi $(100 \%) .{ }^{20}$ Namun dengan adanya banyak perbedaan pendapat tersebut, sulit untuk mencapai persentase sebesar $100 \%$. Maka dari itu peneliti menetapkan persentase level konsensus pada penelitian ini sebesar 60\%. Persentase level konsensus ini sejalan dengan penelitian Moxham et al. ${ }^{10}$ Sementara Swamy et $\mathrm{al}^{11}$ menetapkan persentase yang sangat tinggi yaitu sebesar $94 \%$, Smith et a ${ }^{14}$ sebesar $90 \%$, Munawaroh et a ${ }^{9}$ sebesar $80 \%$, sedangkan Tubbs et a ${ }^{12}$ cenderung agak rendah, yaitu sebesar 50\%.

Pada saat pengisian kuesioner, peneliti menekankan kepada setiap panel untuk menuliskan jawaban sesuai dengan kebutuhan klinis yang sering ditemui di lapangan saat mereka berpraktik sebagai dokter umum serta tidak terlepas dari Standar Kompetensi Dokter Indonesia (SKDI) 2012. SKDI menampilkan daftar kompetensi dokter umum sehingga diharapkan dokter yg dihasilkan dapat memberikan pelayanan terbaik bagi pasiennya. ${ }^{21}$ Berbekal dari sana, diharapkan jawaban yang peneliti terima dari setiap panel sudah menggambarkan klinis atau penyakit yang sering dikeluhkan masyarakat umum kepada para dokter di tingkat primer. Sehingga dengan adanya jawaban dari para panel, materimateri yang terpilih tersebut bisa dipersiapkan untuk pembelajaran mahasiswa kedokteran yang nanti juga akan menjadi dokter di tingkat primer. Dokter umum yang menjadi panel dalam penelitian ini juga mempunyai kriteria lulus dari sekolah kedokteran kurang dari 10 tahun. Tujuannya adalah agar materi anatomi yang didapatkan saat di sekolah kedokteran masih melekat pada memori panel. Selain itu juga agar setiap panel dapat membandingkan materi anatomi yang dahulu sempat dipelajari saat kuliah dan materi anatomi yang dibutuhkan untuk mendukung profesionalisme dalam praktik sekarang.

Dari data penelitian ini didapatkan beberapa alasan dan korelasi klinis mengapa para panel memilih struktur tersebut sebagai materi inti. Sebagai contoh, dengan mengetahui posisi apex cordis dan berbagai valva atau katup dalam jantung, seorang dokter bisa melakukan pemeriksaan fisik seperti auskultasi untuk mengetahui apakah terdapat kelainan katup seperti stenosis ataupun regurgitasi. Baik stenosis maupun regurgitasi tersebut mengakibatkan terganggunya fungsi valva dan pada akhirnya dapat menyebabkan kelainan jantung. ${ }^{16}$ Dalam beberapa review yang membahas tentang elektrofisiologi jantung, dikatakan bahwa sangat penting kemampuan dalam memahami anatomi jantung secara rinci. Setiap mahasiswa kedokteran dalam mempelajari anatomi perlu memahami betul struktur dari jantung yang sakit maupun jantung normal..$^{22}$

Sementara untuk arteri-arteri di extremitas seperti A. radialis yang dipilih untuk menjadi materi inti pada extremitas superior dengan alasan A. radialis merupakan salah satu arteri untuk menilai tanda vital seorang pasien atas indikasi kegawatdaruratan dan untuk pemeriksaan analisis gas darah. A. femoralis untuk kepentingan analisis gas darah dan 
merupakan pembuluh darah yang sering mengalami cedera ketika terjadi fraktur Os. femur. Kemudian A. dorsalis pedis termasuk penting dengan alasan untuk menilai tingkat dehidrasi seorang pasien dan bersama dengan A. tibialis untuk menilai vaskularisasi pasien diabetes melitus. Pada sirkulasi vena, vena cava superior dan vena cava inferior dipilih menjadi materi inti karena merupakan pembuluh vena terbesar dan terpenting untuk melihat sirkulasi darah seorang pasien. Akan tetapi dengan adanya hasil seperti di atas, tidak membatasi mahasiswa kedokteran untuk tetap mempelajari arteri, vena, dan struktur lainnya.

Pengenalan fokus klinis dalam pengajaran ilmu dasar dapat membantu menjembatani kesenjangan antara ilmu dasar anatomi dan praktek klinis. ${ }^{23}$ Sehingga semua sepakat bahwa materi anatomi sangat penting untuk mengintegrasikan konten ilmu dasar dan klinis. ${ }^{24}$ Tidak mudah untuk memahami hubungan antara pengetahuan dan penerapannya dalam praktek klinis. Oleh karena itu pendekatan Delphi dimanfaatkan untuk mengumpulkan pendapat kolektif dari dokter untuk membantu meningkatkan pembelajaran anatomi yang relevan. Informasi klinis yang dikumpulkan dapat membantu mahasiswa untuk menjadi akrab dengan situasi klinis dimana kelak mereka diwajibkan untuk menerapkan pengetahuan anatomi mereka. Ketika mereka akan menghadapi situasi yang sama di praktek klinis, mungkin akan menjadi lebih mudah untuk mengambil tindakan. Jadi tujuan dari pendekatan Delphi adalah untuk menentukan konten anatomi yang penting untuk mendidik dan membantu mahasiswa untuk mengintegrasikan situasi klinis. Hasil yang diinginkan akhirnya adalah untuk menjembatani kesenjangan antara anatomi dan praktek klinis. ${ }^{25}$

Materi inti yang dipilih oleh para panel di kuesioner merupakan materi penting yang memiliki korelasi klinis dan berhubungan dengan penyakit yang banyak dijumpai dipraktik dokter umum. Dengan memiliki pemahaman anatomi yang baik, seorang dokter dapat dengan mudah menegakkan diagnosis dan memberikan edukasi kepada pasien sehingga dapat meningkatkan komunikasi dan hubungan dokter pasien. ${ }^{11}$

Panel yang terlibat dalam penelitian ini berasal dari berbagai daerah di Indonesia. Harapannya hasil ini bisa mewakili pendapat para dokter umum di Indonesia. Daerah tempat praktek yang berbeda memungkinkan para panel menjumpai variasi kasus yang cukup banyak di lapangan. Selain itu dokter umum yang menjadi panel Delphi dalam penelitian ini juga berasal dari berbagai universitas di Indonesia. Sehingga pengalaman belajar mereka pun bervariasi mewakili latar belakang tempat pendidikan masingmasing. Oleh karena itu hasil penelitian ini dapat mewakili variasi pembelajaran di berbagai universitas dan juga variasi kasus yang ditemui dokter umum diberbagai wilayah di Indonesia. Sehingga hasil penelitian ini diharapkan bisa menjadi bahan pertimbangan bagi dosen anatomi pada umumnya dalam menyusun materi pembelajaran anatomi kedokteran dan perhimpunan ahli anatomi Indonesia (PAAI) pada khususnya dalam membuat panduan kurikulum pembelajaran yang dapat dijadikan rujukan resmi seluruh fakultas kedokteran di Indonesia.

Dengan adanya hasil penelitian ini diharapkan materi anatomi menjadi lebih ringkas namun tetap mengacu pada kompetensi dokter umum yang sudah ditetapkan dalam SKDI. Materi anatomi juga diharapkan dapat lebih berkorelasi dengan klinis yang sering ditemui dalam praktek dokter umum sehingga mahasiswa kedokteran tidak jenuh dalam mempelajarinya dan tetap menjadi dokter yang profesional sesuai dengan kompetensinya.

\section{KESIMPULAN}

Konsensus dokter umum mengenai materi inti anatomi sistem sirkulasi yang didapatkan dari hasil penelitian ini adalah sejumlah 110 materi inti dari 270. Materi inti tersebut terdiri dari materi jantung sebanyak 30 poin, pericardium 3 poin, mediastinum 10 poin, pembuluh darah arteri 37 poin, pembuluh darah vena 9 poin, sistem limfatik 9 poin, sirkulasi pascanatal 4 poin, sirkulasi prenatal 5 poin, dan sistem portal hepatis 3 poin.

\section{UCAPAN TERIMAKASIH}

Penulis mengucapkan terima kasih kepada seluruh dokter umum yang telah terlibat dalam penelitian ini dan bersedia dengan tulus mengikuti jalannya penelitian ini dari awal hingga akhir. 


\section{DAFTAR PUSTAKA}

1. Sugand K, Abrahams P, Khurana A. The anatomy of anatomy: A review for its modernization. AnatSci Educ. 2010;3:83-93.

2. Orsbon CP, Kaiser RS, Ross CF. Physician opinions about an anatomy core curriculum: a case for medical imaging and vertical integration. AnatSci Educ. 2014;7:251-61. doi: 10.1002/ase.1401.

3. Vorstenbosch MA, Kooloos JG, Bolhuis SM, Laan RF . An investigation of anatomical competence in junior medical doctors. AnatSci Educ. 2016;9:8-17. doi: $10.1002 /$ ase.1513.

4. Louw G, Eizenberg N, Carmichael SW. Points of anatomy in medical education. Amee Guide, 2009;31: 373-86.

5. Brooks WS, Huitt TW, Killins A. Team-based learning in the gross anatomy laboratory improves academic performance and students' attitudes toward teamwork. AnatSci Educ. 2015;8(2):95-103. doi: 10.1002 /ase. 1460 .

6. Arain NN, Cowan M, Assale TS, Assi AH, Albar RA, Ganguly PK. Student-centered integrated anatomy resource sessions at Alfaisal University. AnatSci Educ. 2010;3(5):272-5. doi: 10.1002/ase.176.

7. Leddy JJ, Whelan A, Mindra S, Hughes JDM, El-Bialy S, Ramnanan CJ. Student Perceptions of Independent Versus Facilitated Small Group Learning Approaches to Compressed Medical Anatomy Education. AnatSciEduc. 2015; in press.

8. Klement BJ, Paulsen DF, Wineski LE. Anatomy as Backbone of the Integrated Medical Curriculum First Year: Design and Implementation. AnatSci Educ. 2011;4(3): 157-69.

9. Munawaroh S, Rahayu GR, Suryadi E. Identification of Anatomy Contents for Medical Students Using Delphi Technique. Jurnal Pendidikan Kedokteran Indonesia. 2017;6(2):98-107.

10. Linstone HA, Turoff M. Delphi survey: method techniques and applications. Read: Addison-Wesley; 1975.

11. Swamy et al. A Delphi consensus study to identify the most prized clinical component of orthopedic anatomy to Teaching medical students. BMC Medical Education. 2014;14:230.

12. Tubbs R, et al. The Development of a core syllabus for the teaching of head and neck anatomy to medical students. Clin. Anat. J, 2014;27(3):321-30.
13. Moxham BJ et al. An Approach Toward the Development of Core Syllabuses for the Anatomical Sciences. Anatomical Sciences Education, 2014;7:302-11.

14. Smith CF, Finn GM, Stewart J, McHanWell S. Anatomical Society core regional anatomy syllabus for undergraduate medicine: the Delphi process. Journal of Anatomy, 2016;228:2-14.

15. Mackellar A, Ashcroft DM, Bell D, James DH, Marriott J. Identify criteria for pharmacy student rating Ability to communicate with patients. Am J Pharm Educ. 2007;71(3):50.

16. Drake RL, Vogl W, Mitchell AWM. Gray's Anatomy for Student. New York: Elsevier; 2014.

17. Moore KL, Dalley AF, Agur, AMR. Clinically Oriented Anatomy. 7th ed. London: Lippincott Williams \& Wilkins; 2014.

18. Paulsen F, Waschke J. Sobotta Atlas of Human Anatomy. 23th ed. Jakarta: EGC; 2012.

19. Hsu CC, Sandford BA. The Delphie Technique: Makes Sense of Censensus, Practical Assessment, Research \& Evaluation, 2007;12(10).

20. Miller LE. Determining what could / should be be: Delphi technique and its application. Paper presented at a meeting of the 2006 annual meeting of Mid-Western Educational Research Association, Columbus, Ohio; 2006.

21. KKI. Standar Kompetensi Dokter Indonesia (SKDI). 2nd ed. Indonesia: Konsil Kedokteran Indonesia; 2012.

22. Lachman N, Hai SHJJ, Syed FF, Desimone CV, Asirvatham SJ. The Anatomical Basis of ventricular arrhythmias in Normal Heart: What Students Need to Know Anatomy.Clin Anat. 2014;27(6):885-93. doi: $10,1002 /$ ca.22362.

23. Murphy KP, Crush L, O'Malley E, et al. Medical student knowledge regarding radiology before and after a radiological anatomy module: implications for vertical integration and self-directed learning. Insights Imaging. 2014;5:629-34. doi: 10.1007/ s13244-014-0346-0.

24. Lachman N, Pawlina W. Integrating professionalism in early medical education: The theory and application of reflective practice in the anatomy curriculum. Clin Anat. 2006;19:456-60. doi: 10.1002/ca.20344

25. Smith CF, Mathias HS. What is the impact of anatomical education on Clinical practice? ClinAnat, 2011;24:113-9. 